Interview

\title{
Interview with Neeske Alexander
}

\author{
Rose Richards $1 *$
}

Published: April 11, 2020

\section{INTRODUCTION}

Neeske Alexander is an academic writer, educator and artist living in Cape Town. She holds BEd (Foundation Phase), BHons (Learning support), BA Visual Arts (Illustration) and MA Visual Arts (Art Education) degrees. She has benefitted from a long-term mentorship under artist Ian Tainton and has received training in several media including oil painting and printmaking. In 2019, Neeske participated in an international comics residency and exhibited at the Angoulême Comics Festival, France. She has taken part in a variety of group exhibitions both nationally and internationally. Neeske has received several awards for her work including a prize in the international Picture This! Illustration competition in 2017 and first prize in the Tollman Bouchard Finlayson Tondo competition in 2019. In addition, she was a finalist in the Sasol New Signatures Award in 2019 and the Artist Magazine still life competition in 2020. Neeske is currently a part-time lecturer at Stellenbosch University.

\section{Who has influenced your work?}

Anton Kannemeyer, co-author of BIT'TERCOMIX and arguably one of the most well-known South African comix artists, was my lecturer and introduced me to narrative illustration and comics in 2018. He encouraged me to read as many comics and comix ${ }^{1}$ as I can and pointed me to some of the classics as well as work on the fringe. I had not read comics since primary school - and then it was only Asterix and Obelix, so I particularly enjoyed reading graphic novels such as Fun Home by Alison Bechdel and Exit Wounds by Rutu Modan. It was Anton, too, who told me to draw every day and to create and sell my first zine Gomtosgollies and Other Stories at the Fancon event in Cape Town in 2019. Finally, it was his connection with comix artists in France that opened up the way for me to attend a residency there in January 2019.

I'm also influenced by those artists I met during my short residency in Angoulême, France, at the beginning of 2019: Anna Haifisch (Germany), Mathilde Van Gheluwe (Belgium), Juliana Hyrri (Finland), Eva Lynen (Belgium). Anna Haifisch and Eva Lynen both have a strong autobiographical approach to their work. I have been influenced by the different approaches these artists take to representing womxn in a visual way. Examples of their work can be found on their Instagram accounts.

\section{What other African artists do you draw inspiration from?}

Octavia Roodt (her work shows the Afrikaner identity in new and interesting dreamscapes) and Kirsten Sims (she pushes the boundaries between narrative illustration and fine art) are two South African artists whose work greatly inspires me. I also draw inspiration from the boldness of Lady Skollie (aka Lara Windvogel) who is not necessarily a comix artist, but whose work shows strong feminist influences. Loyiso Mkize's work shows accurate anatomical illustrations of the human figure and I admire his comics for creating a South African superhero in a South African context. All of these artists have well-populated Instagram accounts where their works can be found.

\footnotetext{
${ }^{1}$ Many artists prefer to use 'comix' as a broad term to include narrative illustration works for adults, works that range from one-panel illustrations to graphic novels, works that are sexual and/or political in nature, and work that is alternative to the mainstream Marvel/superhero comics.
} 
Why do you use comic art?

I think narrative illustration (of which comic art forms a part) is very powerful, not only for telling a story and communicating a message in an easy-to-understand way (as opposed to high art or long texts) but also for reflection and self-discovery. My autobiographical comix 11 Months 1 Week tells the story of my time in South Korea. In the process of making this comic, I managed to work through the many personal issues surfacing from reflection on my experiences in South Korea. Perhaps it is the striving to communicate the story and the repetitive process (thumbnails, rough sketches, editing, final drafts, editing, inking, colouring, digital cleaning) of narrative illustration that helps this reflection process.

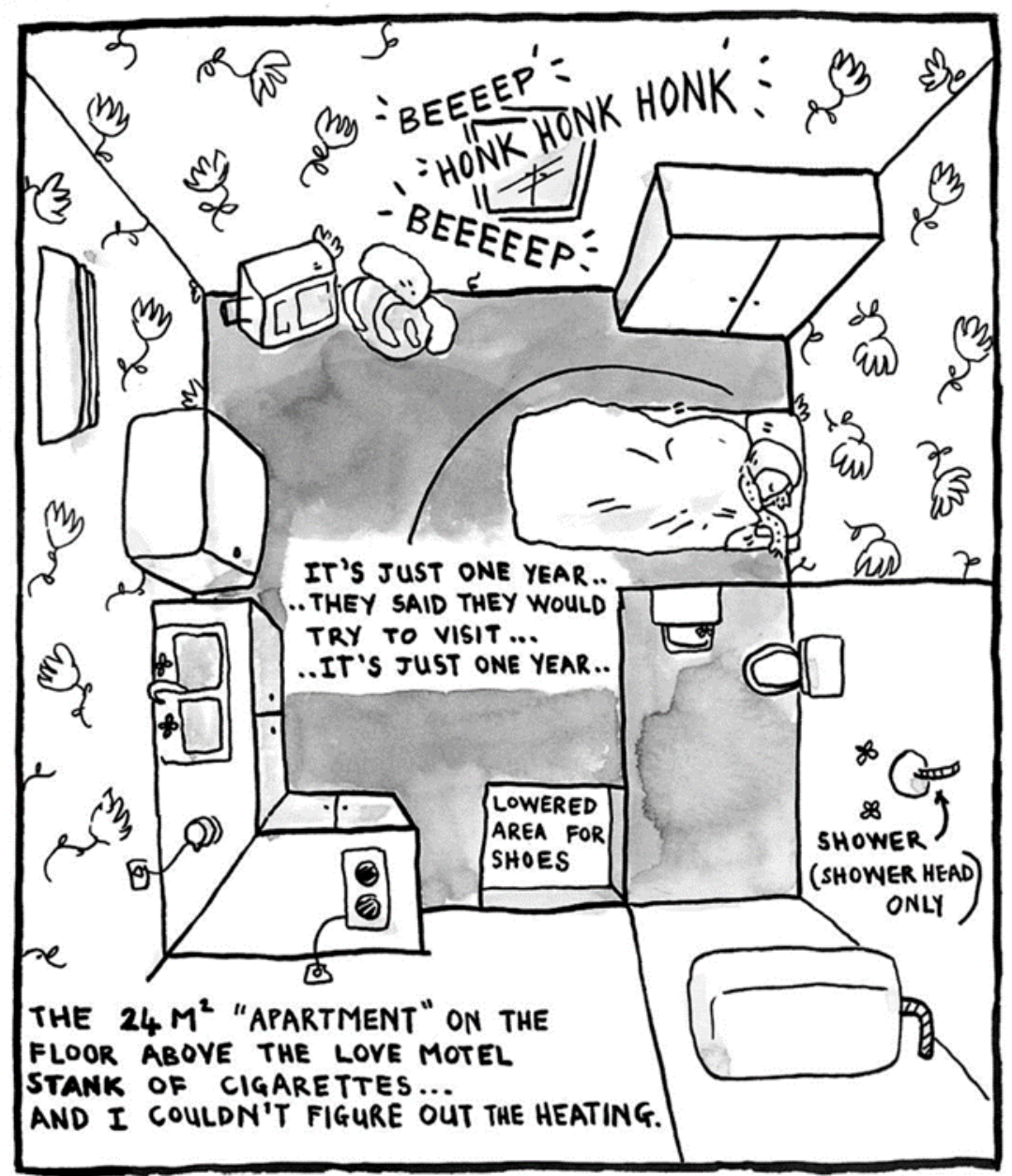

Figure 1. Panel from '11 Months, 1 Week' by Neeske Alexander. (C) Neeske Alexander

Do you think it is a good fit for feminist projects?

Yes. Comix are engaging and, in the visual culture we live in, it is an effective way to communicate - especially online. During my post-graduate illustration degree in 2018, I researched the ways in which narrative illustration and comix could be used to investigate women's stories of menstruation. I called the project The Period Party. This work can be seen as menstrual activism which works against the negative stereotype of menstruation as dirty and shameful. Menstrual activists have used different mediums to promote their cause including parades, poetry, art, installations and digital/paper zines (self-produced and distributed magazines). The use of independent publishing in the feminist movement has a long and rich history. Many comics, especially underground comics, are selfpublished in the form of zines. Chella Quint's zine titled Adventures in Menstruating, is a good example. Quint is a comedian, designer and artist who founded the \#periodpositive campaign. ${ }^{2}$ Other artists who promote menstrual activism include Rupi Kaur and Lucy Peach.

${ }^{2}$ Chella Quint's work can be found here: https://chellaquint.wordpress.com/about/. 
What do you think about 'mainstream' comic book art?

I'm not a fan of the Marvel comic style. I prefer the fringe comics and graphic novels. The artists mentioned in the first few questions create work that are good examples of alternative comix. They draw in new and interesting ways, unlike the generic manga or Marvel style. Drawing in new ways is a good way to communicate new messages.

\section{What difficult issues have you tackled and how?}

As mentioned above, I've written about menstruation. I collected women's stories about menstruation and turned them into comix. Here is an extract from my unpublished article, 'The Period Party':

'Menstruation is something most women experience, yet it is often considered taboo. Ideas about menstruation are socially constructed and the way in which we speak (or don't speak) about it, is not often researched. Elements of taboo, stigma and power are related to perceptions of menstruation which causes menstruation and other corporeal leaks to be associated with shame, disgust, embarrassment and contamination (Grosz, 1994: 206). It is also believed by feminists that menstruation, as a specific 'leak', has been used as a tool to suppress, stigmatise and devalue women. Why is menstruation, which is a vital component of life-creation and part of most women's bodily experience, seen as shameful, stigmatising and taboo? Women should not (be made to) feel shame and disgust and inferiority regarding their menstruation. I therefore ask "How can illustration be used to investigate and communicate stories of menstruation?" For this project, The Period Party, the aim was to create an illustrated book/ visual collection of stories about menstruation and in doing so to make space for women to share their experiences.'

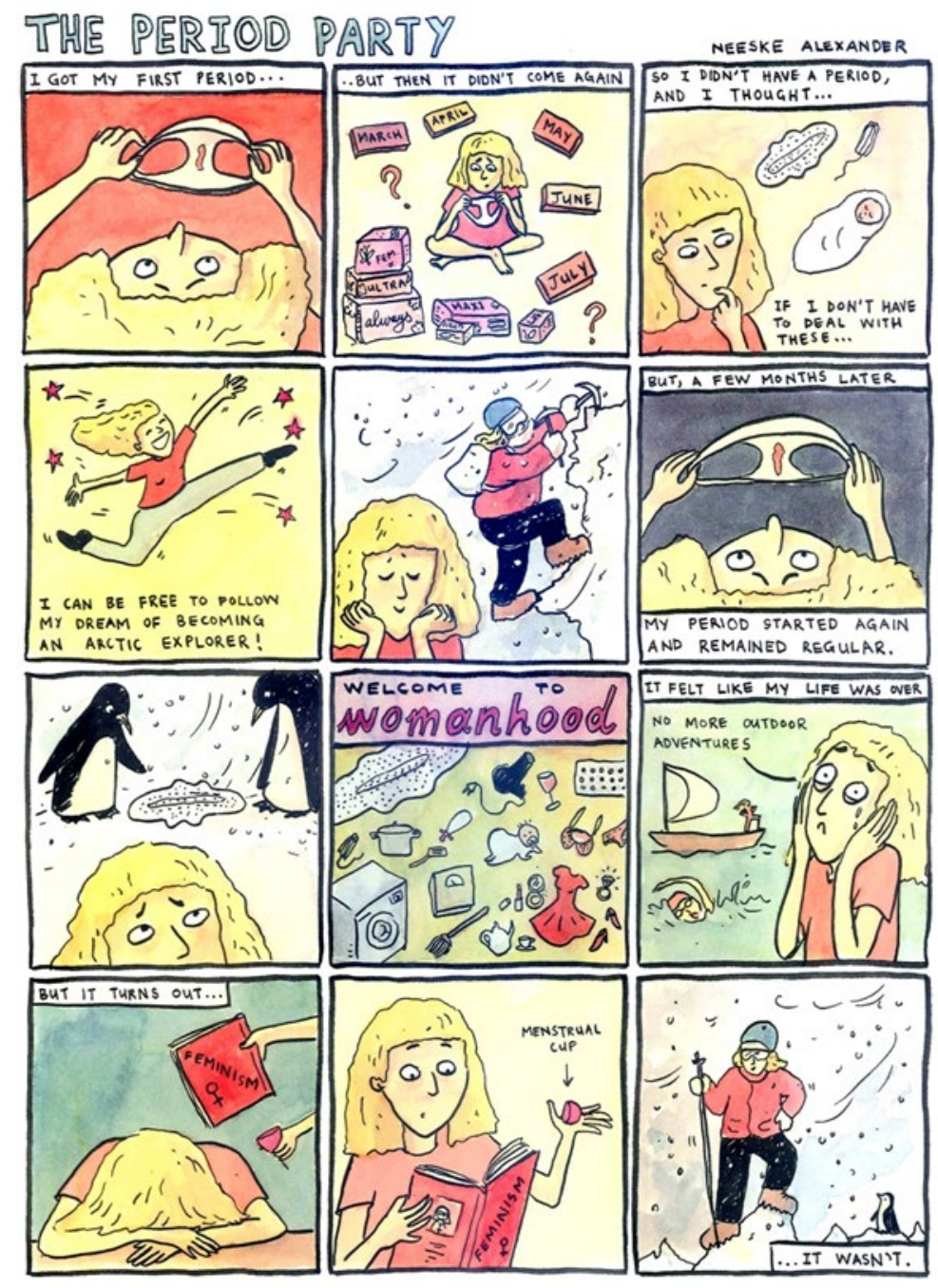

Figure 2. 'The period party' by Neeske Alexander. (C) Neeske Alexander. 
Is it easy to get your work published? What is the comics industry like in South Africa?

I must just mention that I am very new in the comix world. I drew my first comic (11 Months, 1 Week) in 2018 as part of my post-graduate degree. I drew my second set of comics (The Period Party) at the end of 2018 for my research project. I've only self published my comics for events such as Fancon and Open Book Festival in Cape Town. I've also had my comix (The Period Party) exhibited as part of Comic Con in the Joburg Art Gallery in 2019. So, I am not sure that I know what the comics industry is like, but I suspect that most publishers prefer to publish work that will sell - work drawn in the mainstream comics styles.

\section{Who are your readers?}

Most of my readers are probably people on Instagram and those who buy my comix at the events in Cape Town. It is mostly womxn who comment on my Instagram posts and who buy my comix. I hope that my comix about menstruation will fall into the hands of young womxn, because I wish I had had something like that when I first started menstruating.

Is there anything else you would like to add?

I think narrative illustration has untapped power for processing trauma. I draw little comics when something $\mathrm{bad} /$ frustrating happens to me and it helps me to process this experience. Everyone can draw comix and I hope that there will soon be an increase in comix artists in South Africa.

Here is a quick comix sketch about my hatred of dish-washing:
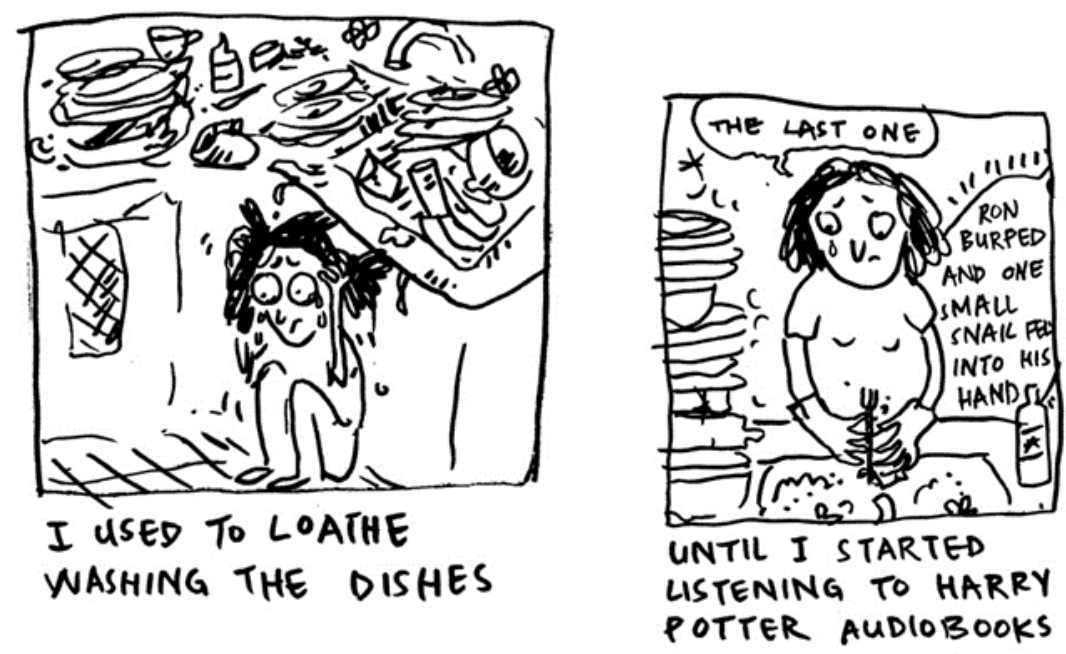

Figure 3. Untitled by Neeske Alexander. (C) Neeske Alexander.

Citation: Richards, R. (2020). Interview with Neeske Alexander. Feminist Encounters: A Journal of Critical Studies in Culture and Politics, 4(1), 11. https:// doi.org/10.20897/femenc/7915

Copyright (C) 2020 by Author/s and Licensed by Lectito BV, Netherlands. This is an open access article distributed under the Creative Commons Attribution License which permits unrestricted use, distribution, and reproduction in any medium, provided the original work is properly cited. 